Research Article

\title{
An Electrically Actuated Liquid-Metal Gain-Reconfigurable Antenna
}

\author{
George B. Zhang (D), Ryan C. Gough, Matthew R. Moorefield, Kareem S. Elassy, \\ Aaron T. Ohta, and Wayne A. Shiroma
}

Department of Electrical Engineering, University of Hawaii at Manoa, 2540 Dole St., Honolulu, HI 96822, USA

Correspondence should be addressed to George B. Zhang; georgez@hawaii.edu

Received 27 December 2017; Accepted 11 March 2018; Published 15 April 2018

Academic Editor: Chien-Jen Wang

Copyright (c) 2018 George B. Zhang et al. This is an open access article distributed under the Creative Commons Attribution License, which permits unrestricted use, distribution, and reproduction in any medium, provided the original work is properly cited.

\begin{abstract}
A tunable liquid-metal antenna demonstrating gain reconfigurability is presented. This antenna uses a reconfigurable stub made with the liquid metal Galinstan. Using continuous electrowetting, a $60 \mathrm{~Hz}$ signal with an amplitude of $1 \mathrm{~V}_{\mathrm{pp}}$ and $75 \%$ duty cycle can actuate the Galinstan continuously along a channel, tuning the stub length and antenna gain. Zero external power is required to maintain the position of the slug. The $5 \mathrm{GHz}$ antenna offers more than $10 \mathrm{~dB}$ of analog gain tuning, from -5.90 to $4.43 \mathrm{~dB}$.
\end{abstract}

\section{Introduction}

Reconfigurable antennas have become increasingly important for modern wireless communication systems [1,2]. Reconfigurability has been effectively implemented using PIN diodes [3], varactors [4], and MEMS switches [5]. However, these discrete elements often limit the number and range of states [6].

Liquid metal, capable of assuming arbitrary shapes, offers the potential for the analog tunability of antenna parameters such as frequency, polarization, and gain over a wide range. Liquid metal has been used to implement the three conventional types of antenna reconfigurability [2]: frequency reconfigurability [6-9], polarization reconfigurability [10-12], and pattern reconfigurability [13-15]. This work explores gain reconfigurability, which not only can adjust communication range, but may also find uses in networks with interference. In interference networks, even small adjustments in antenna gain can lead to large gains in communication capacity [16].

The antenna presented in this work is gain reconfigurable in the strict sense that the shape of the radiation pattern remains roughly the same as the gain (defined here as the peak gain within the given measurement planes) varies.
Moreover, the presented antenna offers analog gain reconfigurability, rather than gain tuning that is limited to discrete states. The closest example of a gain-reconfigurable antenna using liquid metal is reported in [17]. In that paper, a liquidmetal spiral antenna printed on an inflatable hemispherical elastomer demonstrated a continuous tunable directivity of $2.34 \mathrm{~dB}$.

The liquid-metal antenna presented here is electrically actuated with a $60 \mathrm{~Hz}, 1 \mathrm{~V}_{\mathrm{pp}}, 75 \%$-duty-cycle signal only when the gain is tuned. No applied signal is required to maintain the antenna gain after tuning. Previous liquid-metal antennas are either actuated by pressure [7, 8, 13-17], require higher actuation voltages $[12,13]$, or require a constant bias to maintain its operating state [10].

The antenna presented is novel in that it offers the following three features simultaneously: (1) low-voltage $\left(1 \mathrm{~V}_{\mathrm{pp}}\right)$ electrical actuation, (2) zero external power required to maintain each gain state, and (3) more than $10 \mathrm{~dB}$ of analog gain tuning.

\section{Design}

2.1. Copper-Baseline Antenna. Copper was first used instead of liquid metal to measure baseline antenna performance. 


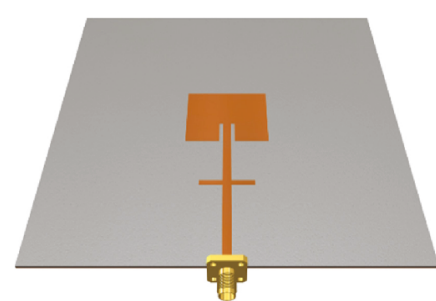

(a) $0 \mathrm{~mm}$ offset state

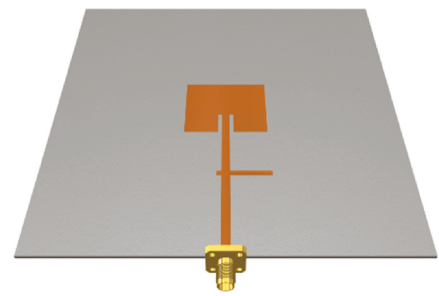

(c) $5 \mathrm{~mm}$ offset state

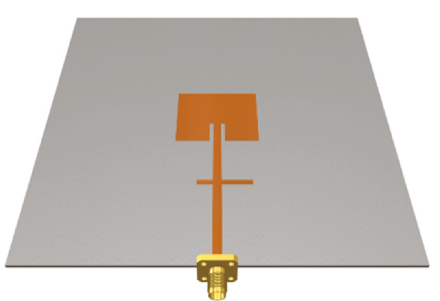

(b) $2 \mathrm{~mm}$ offset state

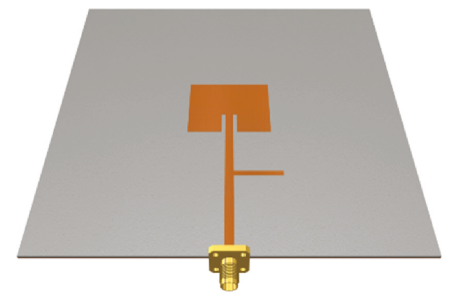

(d) $7 \mathrm{~mm}$ offset state

FiguRE 1: Copper-baseline gain-reconfigurable antenna states: (a) $0 \mathrm{~mm}$ offset state: the midpoint of the copper stub coincides with the center of the $50 \Omega$ copper microstrip feed line; (b)-(d) $X$-mm-offset state: the midpoint of the copper stub is $X$ mm from the center of the microstrip feed line. Note that the copper stub is $15 \times 1.5 \times 0.1 \mathrm{~mm}^{3}$.

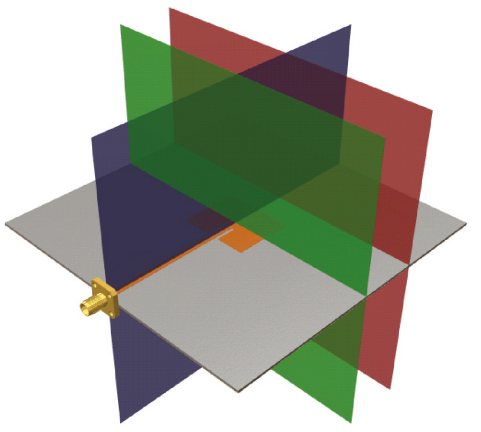

(a)

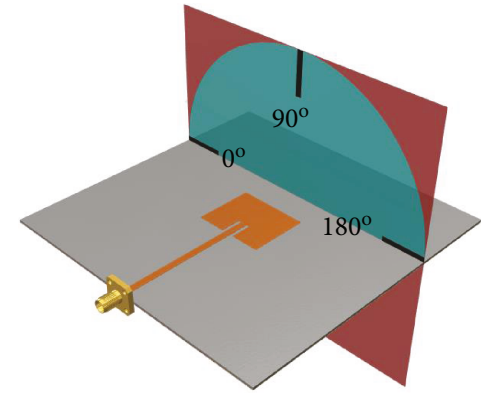

(b)

FIgURE 2: Antenna planes: (a) E-plane (blue), $H$-plane (green), and simulation/measurement plane (red) offset from the $H$-plane by $20 \mathrm{~mm}$; (b) simulation/measurement plane angle range of interest (cyan).

The copper antenna consists of a $0.1 \mathrm{~mm}$ thick $5 \mathrm{GHz}$ copper patch $\left(23.7 \times 19.8 \mathrm{~mm}^{2}\right)$ with feed line insets $\left(1 \times 6.96 \mathrm{~mm}^{2}\right)$, a copper stub $\left(15 \times 1.5 \mathrm{~mm}^{2}\right)$, a quarter free-space wavelength $\lambda_{\mathrm{o}} / 4(15 \mathrm{~mm})$ away from the patch, and a copper $50 \Omega$ microstrip feed line $\left(2.35 \times 40 \mathrm{~mm}^{2}\right)$ on a Rogers 5880 RT/duroid ${ }^{\circledR}$ substrate $\left(100 \times 100 \times 0.79 \mathrm{~mm}^{3}\right)$ with a $35 \mu \mathrm{m}$ thick copper ground plane on the underside (Figure 1). Shifting the stub left and right can continuously tune the gain of the antenna. A total of 15 discrete states were simulated, termed the $0 \mathrm{~mm}, 0.5 \mathrm{~mm}, 1 \mathrm{~mm}, 1.5 \mathrm{~mm}, 2 \mathrm{~mm}$, $2.5 \mathrm{~mm}, 3 \mathrm{~mm}, 3.5 \mathrm{~mm}, 4 \mathrm{~mm}, 4.5 \mathrm{~mm}, 5 \mathrm{~mm}, 5.5 \mathrm{~mm}$, $6 \mathrm{~mm}, 6.5 \mathrm{~mm}$, and $7 \mathrm{~mm}$ offset states. The midpoint of the copper stub located $X \mathrm{~mm}$ to the right of the center of the microstrip feed line constitutes the $X$-mm-offset state.

2.2. Copper-Baseline Antenna Simulations. Gain simulations and measurements were taken in a plane offset from the $H$-plane by $20 \mathrm{~mm}$, as shown in Figure 2(a). Figure 3(a) shows the simulated gains of all 15 considered states for both a matched $50 \Omega$ inset-fed and unmatched $245 \Omega$ edge-fed copper antenna. All simulations were conducted in ANSYS HFSS. In Figure 3(a), the parabola about each $X$-mm-offset represents the $180^{\circ}$ gain pattern above the antenna in the plane shown in Figure 2(b). Both the matched $50 \Omega$ insetfed antenna and the unmatched $245 \Omega$ edge-fed antenna have radiation patterns typical of a patch antenna, with maximum gain at $90^{\circ}$ as defined in Figure 2(b).

The green and orange lines track the maximum gains of the matched $50 \Omega$ inset-fed (red lines) and unmatched $245 \Omega$ edge-fed (blue lines) copper antennas. The green and orange lines tracking the maximum gains are isolated in Figure 3(b). Note that the unmatched $245 \Omega$ edge-fed antenna demonstrates more gain variability than the matched $50 \Omega$ inset-fed antenna. Thus, for a greater gain tuning range, it was preferable to use an unmatched edge feed.

2.3. Liquid-Metal Antenna: Design and Operation. While the copper-baseline antenna proved that gain tuning is possible, it is not possible to realize the tuning with a static copper stub. Thus, a liquid-metal antenna was designed that uses 


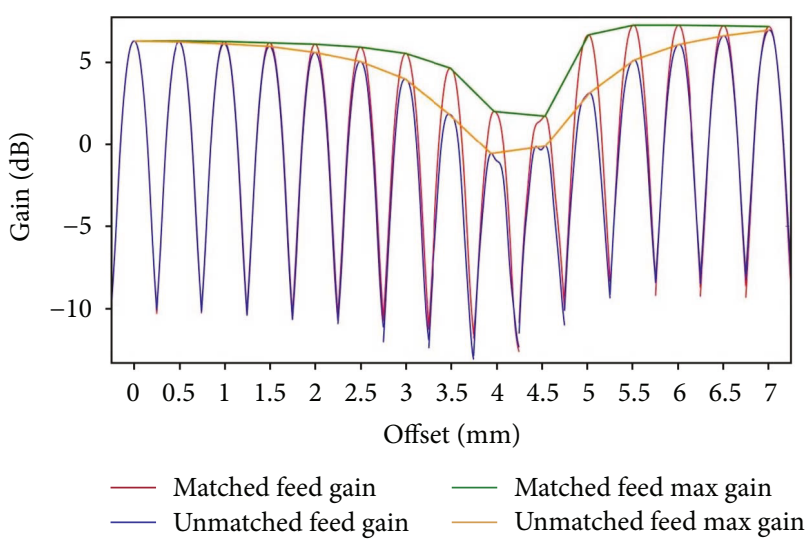

(a)

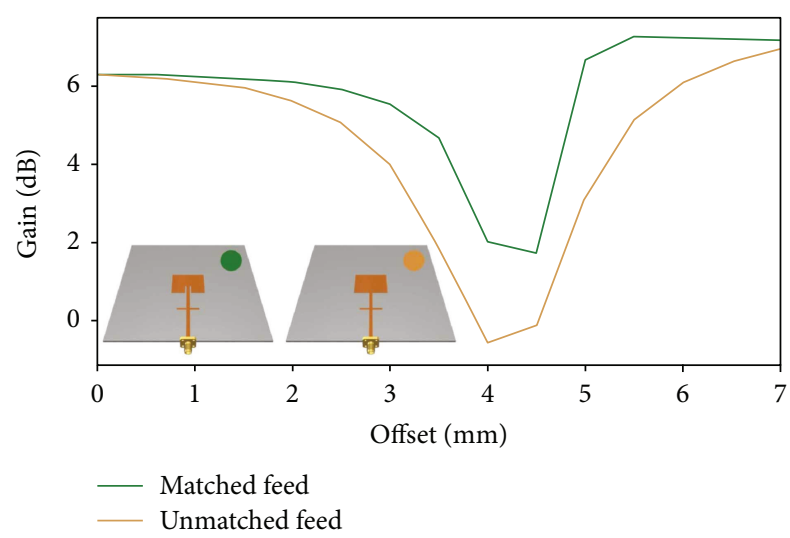

(b)

FIGURE 3: Simulated matched $50 \Omega$ inset-fed copper antenna versus simulated unmatched $245 \Omega$ edge-fed copper antenna: (a) simulated gains of 15 states; (b) simulated maximum gains of 15 states.

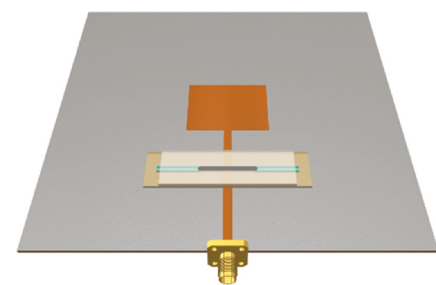

(a) $0 \mathrm{~mm}$ offset state

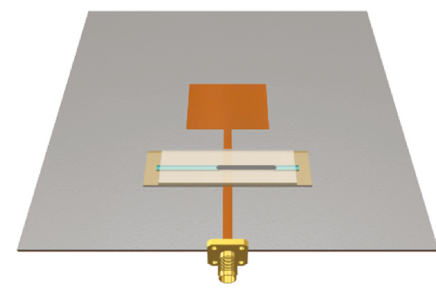

(c) $5 \mathrm{~mm}$ offset state

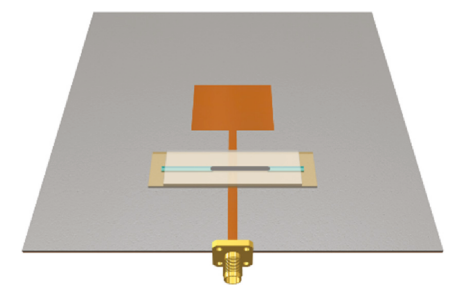

(b) $2 \mathrm{~mm}$ offset state

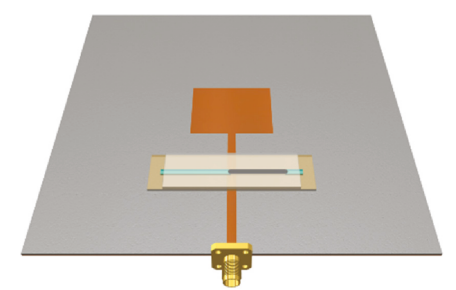

(d) $7 \mathrm{~mm}$ offset state

FIGURE 4: Liquid-metal gain-reconfigurable antenna states. (a) $0 \mathrm{~mm}$ offset state: the midpoint of the Galinstan slug coincides with the center of the $50 \Omega$ copper microstrip feed line; (b)-(d) $X$-mm-offset state: the midpoint of the Galinstan slug is $X$ mm from the center of the microstrip feed line. The Galinstan slug is $1.5 \times 15 \times 0.6 \mathrm{~mm}^{3}$.

a liquid-metal slug in place of the copper stub, as shown in Figure 4. The liquid-metal slug is approximately $15 \times 1.5 \times 0.6 \mathrm{~mm}^{3}$, and consists of a gallium alloy with the trade name of Galinstan. The Galinstan slug has the same dimensions as the copper stub, although it is six times thicker and less conductive $\left(2.3 \times 10^{6} \mathrm{~S} / \mathrm{m}\right.$ for Galinstan [18] versus $5.88 \times 10^{7} \mathrm{~S} / \mathrm{m}$ for copper) than the copper stub.

Gallium-based liquid-metal alloys form a thin oxide skin when exposed to oxygen [18]. The oxidized liquid metal wets to many surfaces, interfering with actuation. To remove this oxide skin, and to enable actuation of the liquid metal by continuous electrowetting (CEW), the Galinstan slug is immersed in a $1 \mathrm{M}(4 \% w / w) \mathrm{NaOH}$ solution [19], which is slightly conductive at low frequencies $(\sim 15 \mathrm{~S} / \mathrm{m}[20])$ and has a high dielectric constant, $\varepsilon_{\mathrm{r}} \simeq 65$ [21]. Thus, the simulated results of the liquid-metal antenna are expected to have different trends compared to the simulated results of the copper-baseline antenna.
Figure 5(a) shows the liquid-metal antenna structure. The top four layers form the liquid-metal fixture. The top $12 \times 36 \times 1 \mathrm{~mm}^{3}$ layer is borosilicate glass (Fisherfinest premium microscope slides) with $\varepsilon_{\mathrm{r}} \simeq 4.3$, and the second and third layers are polyimide (DuPont ${ }^{\mathrm{TM}}$ Kapton $^{\circledR}$ ) with $\varepsilon_{\mathrm{r}} \simeq 3.5$. The second $12 \times 44 \times 0.6 \mathrm{~mm}^{3}$ polyimide layer has a $1.5 \times 38 \times 0.6 \mathrm{~mm}^{3}$ channel for the Galinstan and $\mathrm{NaOH}$. The third $12 \times 44 \times 0.1 \mathrm{~mm}^{3}$ polyimide layer has a $0.625 \mathrm{~mm}$ radius via to allow the Galinstan to contact a $50 \Omega$ copper microstrip feed line below. The fourth $0.1 \mathrm{~mm}$ thick polyimide layer serves to level the surface (which has $0.1 \mathrm{~mm}$ thick copper on it) for the above layers. The $5 \mathrm{GHz}$ patch antenna is identical to the patch in Figure 1. Figure 5(b) shows the fabricated prototype.

In continuous electrowetting (CEW), a voltage applied across an electrolyte submerging a liquid-metal slug induces the motion of the slug [19]. Figure 6 shows the CEW actuation process. The actuation signal only needs to be applied 


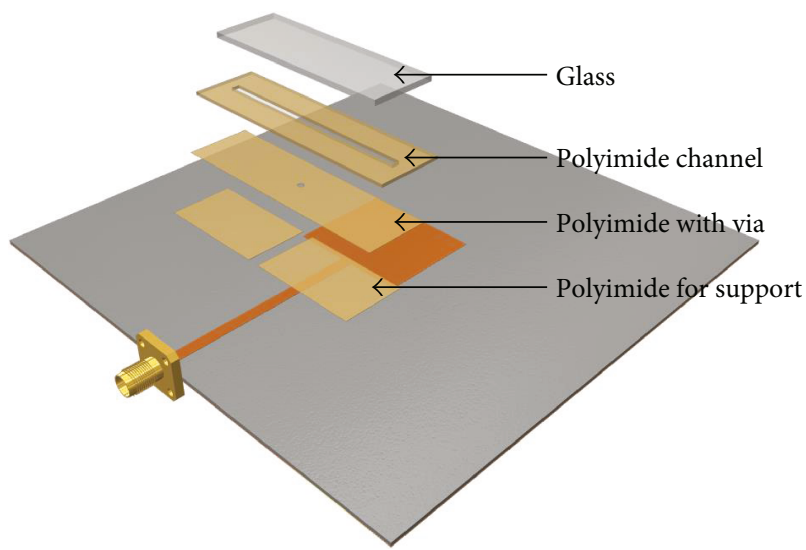

(a)

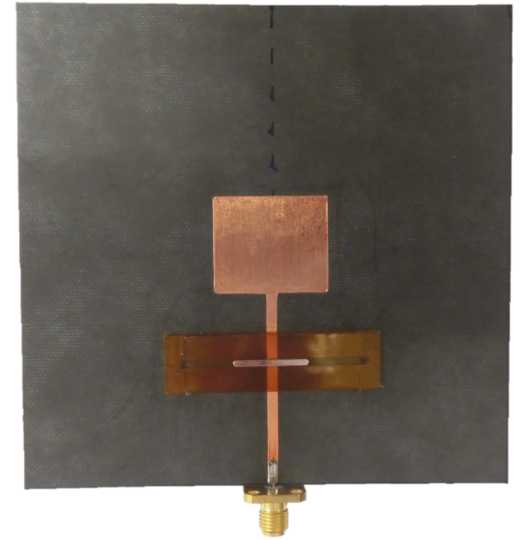

(b)

FIGURE 5: Liquid-metal gain-reconfigurable antenna: (a) exploded view; (b) fabricated prototype.

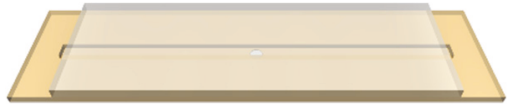

(a) Empty fixture

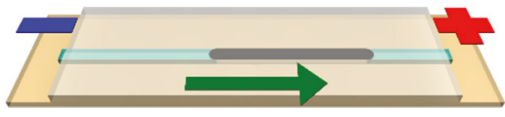

(c) CEW actuation

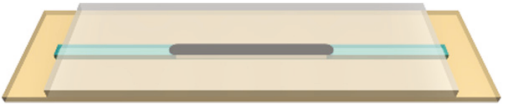

(b) $0 \mathrm{~mm}$ offset state

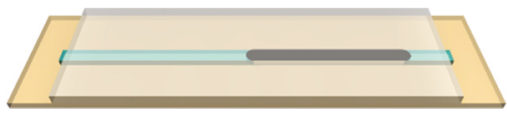

(d) $7 \mathrm{~mm}$ offset state

FIGURE 6: Liquid-metal actuation process: (a) empty fixture; (b) Galinstan slug resting in the $0 \mathrm{~mm}$ offset state (center) submerged in NaOH (cyan); (c) the $\mathrm{NaOH}$ at the left of the channel is grounded (blue negative sign) and a $60 \mathrm{~Hz}, 1 \mathrm{~V}_{\mathrm{pp}}, 75 \%$-duty-cycle signal (red plus sign) is applied to the $\mathrm{NaOH}$ at the right end of the channel, inducing CEW and actuating the Galinstan slug rightward; (d) the Galinstan slug resting in an $X$-mm-offset state ( $7 \mathrm{~mm}$ offset here) does not need an applied potential to remain in position. The entire process can be reversed by reversing the locations in which the AC signal and ground are applied.

to move the liquid metal; no power is required when the antenna maintains a particular state. Once the Galinstan slug is located at a specific offset state, it remains in position as long as the antenna is not tilted. Although not implemented in this paper, greater stability of the slug position can be achieved by adding minimum-surface-energy states to the channel, as demonstrated in [19].

\subsection{Liquid-Metal Gain-Reconfigurable Antenna Simulations.} Figure 7 (a) shows the simulated gains of 15 states for both a matched $50 \Omega$ inset-fed and unmatched $245 \Omega$ edge-fed liquid-metal antenna. The contrast in the gain versus offset in Figure 7 compared to that of Figure 3 is due to the polyimide superstrate, resulting in a change in stub characteristic impedance for the copper-baseline antenna compared to the Galinstan-based antenna. According to Figure 7(b), the matched $50 \Omega$ inset-fed antenna can have its gain tuned from $0.87 \mathrm{~dB}$ to $6.25 \mathrm{~dB}$ (a $5.38 \mathrm{~dB}$ tuning range), and the unmatched $245 \Omega$ edge-fed antenna can have its gain tuned from $-6.21 \mathrm{~dB}$ to $4.66 \mathrm{~dB}$ (a $10.88 \mathrm{~dB}$ tuning range). Again, the unmatched feed yields more gain variability than the matched feed. Thus, the unmatched $245 \Omega$ edge-fed liquidmetal antenna was chosen for fabrication.

Figures 8(a) and 8(b) show the simulated $S_{11}$ and the $360^{\circ}$ gain pattern corresponding to the four states in Figure 4, respectively. The $S_{11}$ values of the various states at the operating frequency of $5 \mathrm{GHz}$ are relatively poor for a typical antenna; however, the purpose of this antenna is to maximize gain tunability to increase capacity in a communication system with interference [16]. Thus, although the unmatched edge-fed antenna results in these less-than-ideal $S_{11}$ values, it was chosen over the matched inset-fed antenna due to the larger range of obtainable gain values. The unmatched edge-fed antenna has radiation patterns typical of a patch antenna, with the maximum gain at $90^{\circ}$.

\section{Experimental Results}

A $60 \mathrm{~Hz}, 1 \mathrm{~V}_{\mathrm{pp}}$, 75\%-duty-cycle signal reliably actuates the $15 \mathrm{~mm}$ Galinstan slug back and forth. It takes $2.23 \mathrm{~s}$ to actuate the slug from the far left $(-7 \mathrm{~mm}$ offset state) to the far right $(7 \mathrm{~mm}$ offset state), a speed of $3.14 \mathrm{~mm} / \mathrm{s}$. Slightly overfilling the channel with $\mathrm{NaOH}$ significantly boosts the actuation speeds to $19.44 \mathrm{~mm} / \mathrm{s}$. Greater voltages can yield higher speeds, e.g., a $60 \mathrm{~Hz}, 3 \mathrm{~V}_{\mathrm{pp}}, 75 \%$-duty-cycle signal actuates the slug at $35.0 \mathrm{~mm} / \mathrm{s}$ in a channel slightly overfilled with $\mathrm{NaOH}$.

Since the actuation was manually controlled by the user, a slower actuation speed was desirable to move the Galinstan slug in submillimeter increments. Thus, the $3.14 \mathrm{~mm} / \mathrm{s}$ actuation offered by the $60 \mathrm{~Hz}, 1 \mathrm{~V}_{\mathrm{pp}}, 75 \%$-duty-cycle signal in a nonoverfilled channel was used. 


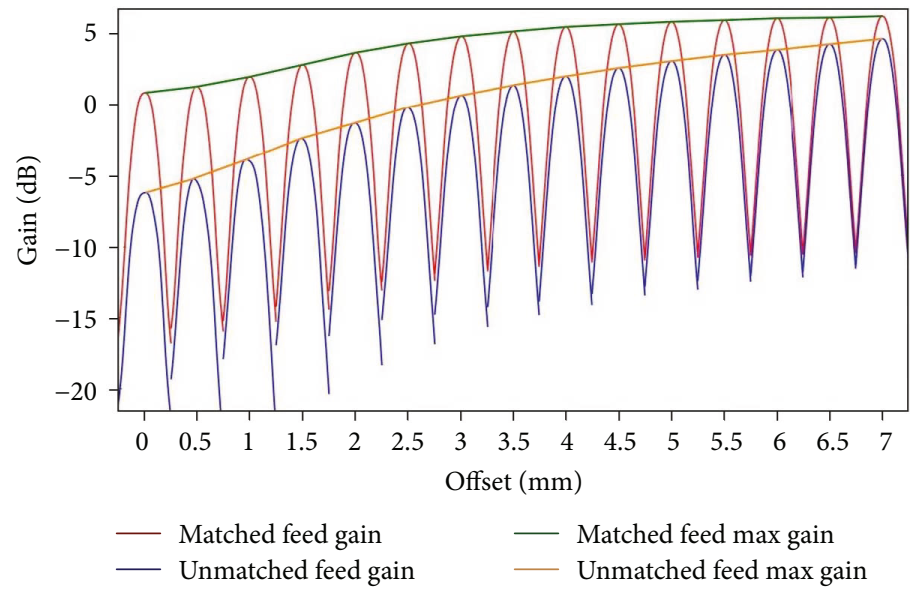

(a)

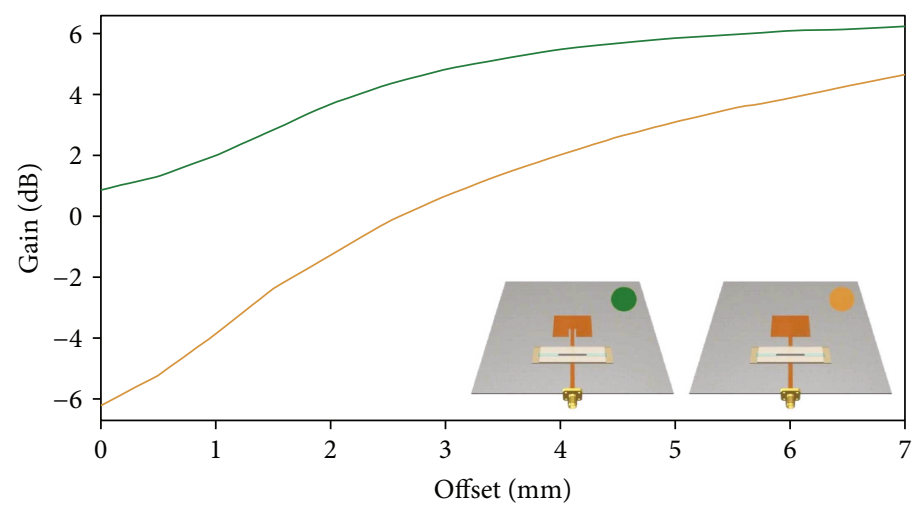

- Matched feed

— Unmatched feed

(b)

FIGURE 7: Simulated matched $50 \Omega$ inset-fed liquid-metal antenna versus simulated unmatched $245 \Omega$ edge-fed liquid-metal antenna: (a) simulated gains of 15 states; (b) simulated maximum gains of 15 states.

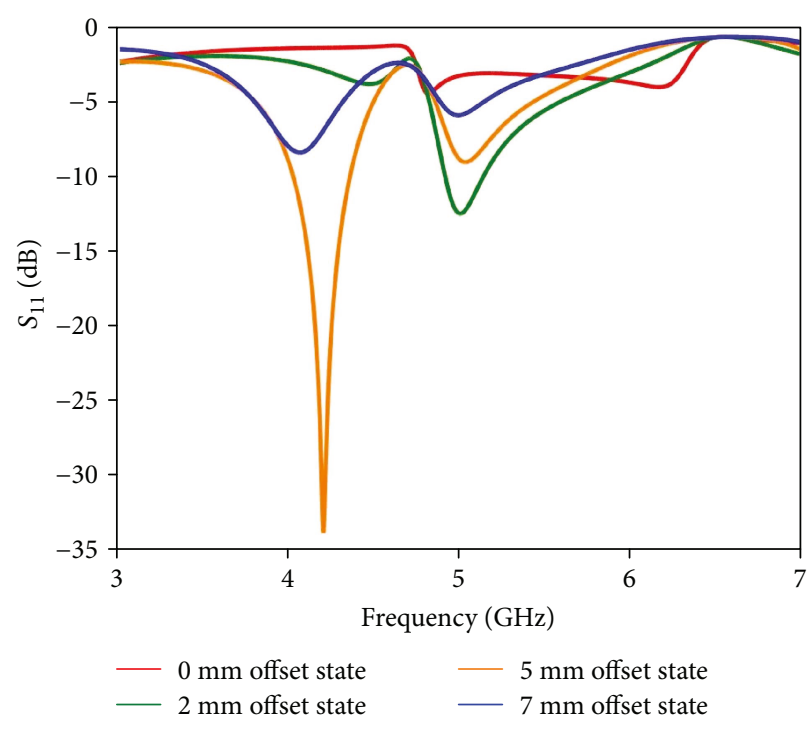

(a)

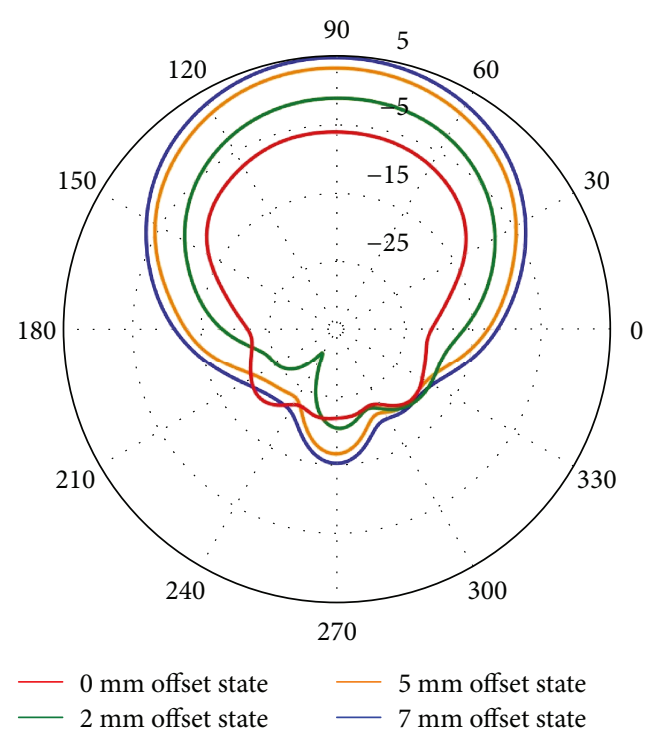

(b)

Figure 8: Simulated (a) $S_{11}$ and (b) gain of the states corresponding to Figure 4 . 


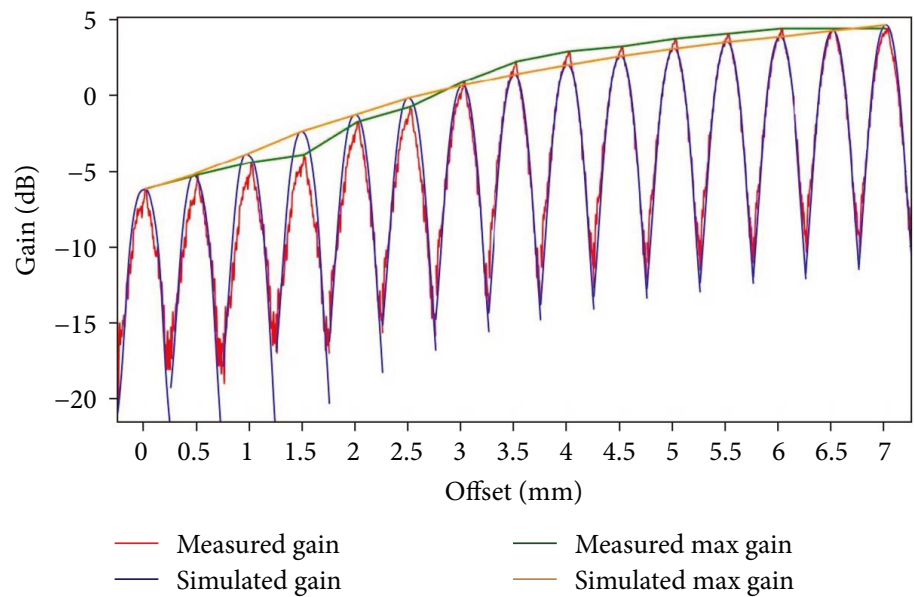

(a)

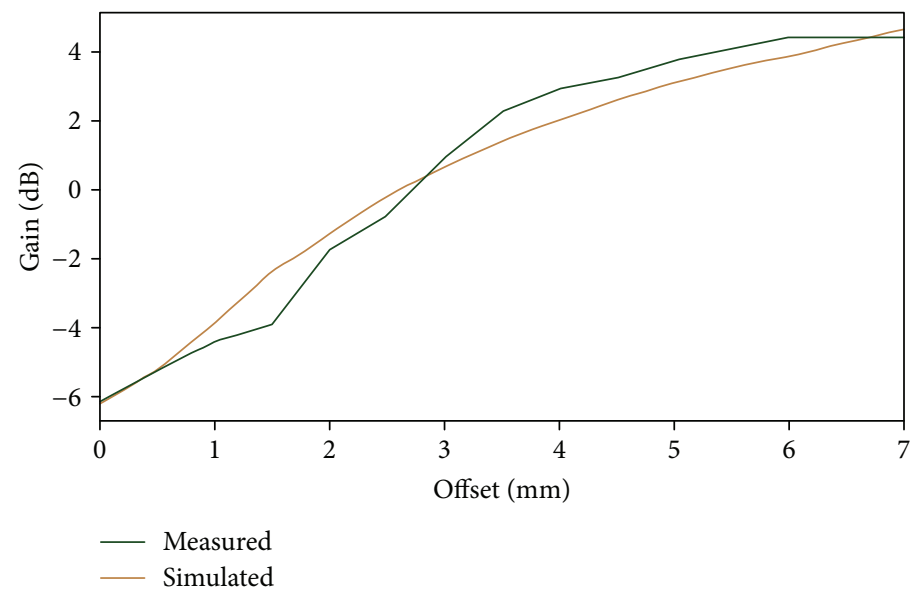

(b)

FIGURE 9: Measured unmatched $245 \Omega$ edge-fed liquid-metal antenna versus simulated unmatched $245 \Omega$ edge-fed liquid-metal antenna: (a) measured and simulated gains of 15 states; (b) measured and simulated maximum gains of 15 states.

Figure 9(a) shows the measured and simulated gains of all 15 considered states for the unmatched $245 \Omega$ edge-fed liquid-metal gain-reconfigurable antenna in Figure 5(b). Once the Galinstan slug is positioned at the desired offset state, the actuating electrodes are detached, leaving the slug in place. Gain measurements were then taken with a horn antenna rotated at a constant distance greater than $10 \lambda_{\mathrm{o}}$ from the test antenna within the measurement planes indicated in Figure 2.

There is strong correlation between measurements and simulation. According to Figure 9(b), the liquid-metal antenna can have its gain tuned from $-5.90 \mathrm{~dB}$ to $4.43 \mathrm{~dB}$ (a $10.33 \mathrm{~dB}$ tuning range). This is close to the simulated tuning range value of $10.88 \mathrm{~dB}$ discussed previously.

Finally, note that by symmetry, the $-X$-mm-offset state should mirror the performance of the $X$-mm-offset state.

\section{Conclusion}

This paper demonstrated the first low-voltage electrically actuated liquid-metal antenna with a $>10 \mathrm{~dB}$ analog gain tuning range $(-5.90 \mathrm{~dB}$ to $4.43 \mathrm{~dB})$. In practice, it may be necessary to replace the straight channel with a channel that has discrete surface energy minima, such as a channel that consists of interlocking circles [19] or a rail and notch scheme $[11,22]$. This can help to hold the liquid metal in place against unintentional motion, although this sacrifices analog tunability for enhanced positioning precision and robustness.

\section{Conflicts of Interest}

The authors declare that they have no conflicts of interest.

\section{Acknowledgments}

This work was supported in part by the National Science Foundation under Grant no. ECCS-1546980.

\section{References}

[1] C. G. Christodoulou, Y. Tawk, S. A. Lane, and S. R. Erwin, "Reconfigurable antennas for wireless and space applications," Proceedings of the IEEE, vol. 100, no. 7, pp. 2250-2261, 2012. 
[2] J. Costantine, Y. Tawk, S. E. Barbin, and C. G. Christodoulou, "Reconfigurable antennas: design and applications," Proceedings of the IEEE, vol. 103, no. 3, pp. 424-437, 2015.

[3] R. Jothi Chitra and V. Nagarajan, "Frequency reconfigurable antenna using PIN diodes," in 2014 Twentieth National Conference on Communications (NCC), pp. 1-4, Kanpur, India, Febuary-March 2014.

[4] N. Behdad and K. Sarabandi, "Dual-band reconfigurable antenna with a very wide tunability range," IEEE Transactions on Antennas and Propagation, vol. 54, no. 2, pp. 409416, 2006.

[5] B. A. Cetiner, H. Jafarkhani, J.-Y. Qian, H. J. Yoo, A. Grau, and F. De Flaviis, "Multifunctional reconfigurable MEMS integrated antennas for adaptive MIMO systems," IEEE Communications Magazine, vol. 42, no. 12, pp. 62-70, 2004.

[6] M. Wang, C. Trlica, M. R. Khan, M. D. Dickey, and J. J. Adams, "A reconfigurable liquid metal antenna driven by electrochemically controlled capillarity," Journal of Applied Physics, vol. 117, no. 19, article 194901, 2015.

[7] J. H. Dang, R. C. Gough, A. M. Morishita, A. T. Ohta, and W. A. Shiroma, "Liquid-metal frequency-reconfigurable slot antenna using air-bubble actuation," Electronics Letters, vol. 51, no. 21, pp. 1630-1632, 2015.

[8] M. Kelley, C. Koo, H. McQuilken et al., "Frequency reconfigurable patch antenna using liquid metal as switching mechanism," Electronics Letters, vol. 49, no. 22, pp. 1370-1371, 2013.

[9] R. C. Gough, J. H. Dang, A. M. Morishita, A. T. Ohta, and W. A. Shiroma, "Frequency-tunable slot antenna using continuous electrowetting of liquid metal," in 2014 IEEE MTT-S International Microwave Symposium (IMS2014), pp. 1-4, Tampa, FL, USA, June 2014.

[10] M. Wang, M. R. Khan, M. D. Dickey, and J. J. Adams, "A compound frequency- and polarization-reconfigurable crossed dipole using multidirectional spreading of liquid metal," IEEE Antennas and Wireless Propagation Letters, vol. 16, pp. 7982, 2016.

[11] G. B. Zhang, R. C. Gough, M. R. Moorefield, K. J. Cho, A. T. Ohta, and W. A. Shiroma, "A liquid-metal polarizationpattern-reconfigurable dipole antenna," IEEE Antennas and Wireless Propagation Letters, vol. 17, no. 1, pp. 50-53, 2017.

[12] S. Yee, D. Weinstein, J. Fiering, D. White, and A. Duwel, "A miniature reconfigurable circularly polarized antenna using liquid microswitches," in 2015 IEEE 16th Annual Wireless and Microwave Technology Conference (WAMICON), pp. 1-5, Cocoa Beach, FL, USA, April 2015.

[13] D. Rodrigo, L. Jofre, and B. A. Cetiner, "Circular beamsteering reconfigurable antenna with liquid metal parasitics," IEEE Transactions on Antennas and Propagation, vol. 60, no. 4, pp. 1796-1802, 2012.

[14] H. Moghadas, M. Zandvakili, D. Sameoto, and P. Mousavi, "Beam-reconfigurable aperture antenna by stretching or reshaping of a flexible surface," IEEE Antennas and Wireless Propagation Letters, vol. 16, pp. 1337-1340, 2016.

[15] A. M. Morishita, C. K. Y. Kitamura, A. T. Ohta, and W. A. Shiroma, "A liquid-metal monopole array with tunable frequency, gain, and beam steering," IEEE Antennas and Wireless Propagation Letters, vol. 12, pp. 1388-1391, 2013.

[16] M. U. Baig, A. Høst-Madsen, and A. Nosratinia, "Discrete modulation for interference mitigation," in 2017 IEEE International Symposium on Information Theory (ISIT), pp. 14361440, Aachen, Germany, June 2017.
[17] P. Liu, S. Yang, X. Wang, M. Yang, J. Song, and L. Dong, "Directivity-reconfigurable wideband two-arm spiral antenna," IEEE Antennas and Wireless Propagation Letters, vol. 16, pp. 6669, 2016.

[18] T. Liu, P. Sen, and C.-J. Kim, "Characterization of nontoxic liquid-metal alloy Galinstan for applications in microdevices," Journal of Microelectromechanical Systems, vol. 21, no. 2, pp. 443-450, 2012.

[19] R. C. Gough, A. M. Morishita, J. H. Dang, W. Hu, W. A. Shiroma, and A. T. Ohta, "Continuous electrowetting of non-toxic liquid metal for RF applications," IEEE Access, vol. 2, pp. 874-882, 2014.

[20] C. F. Lehn, "Chemical solution dispenser apparatus and method of use thereof," EU Patent 0229 038, 1987.

[21] J. M. Mollerup and M. P. Breil, "Modeling the permittivity of electrolyte solutions," AIChE Journal, vol. 61, no. 9, pp. 2854-2860, 2015.

[22] G. B. Zhang, R. C. Gough, M. R. Moorefield, A. T. Ohta, and W. A. Shiroma, "An electrically actuated liquid-metal switch with metastable switching states," in 2016 IEEE MTT-S International Microwave Symposium (IMS), pp. 1-4, San Francisco, CA, USA, May 2016. 


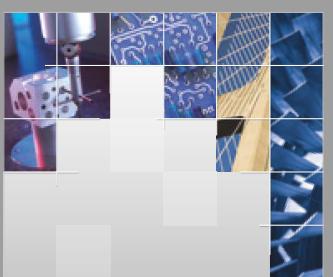

\section{Enfincering}
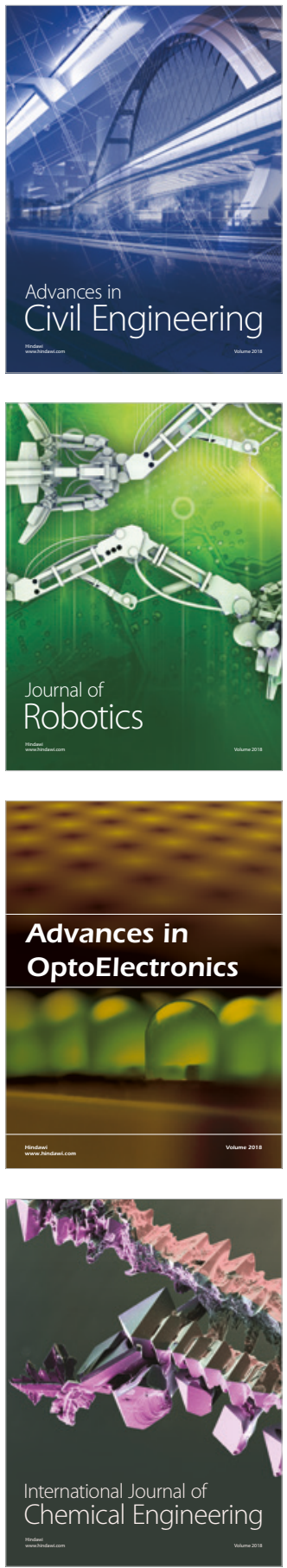

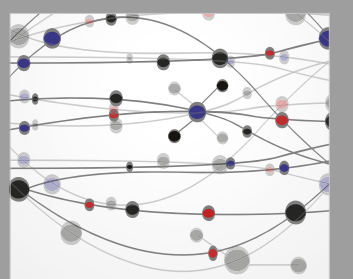

\section{Rotating \\ Machinery}

The Scientific World Journal

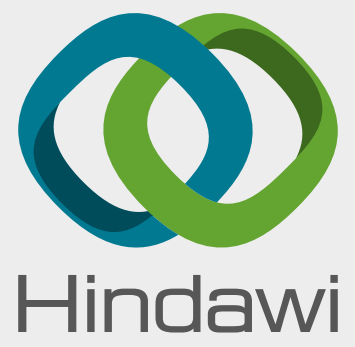

Submit your manuscripts at

www.hindawi.com
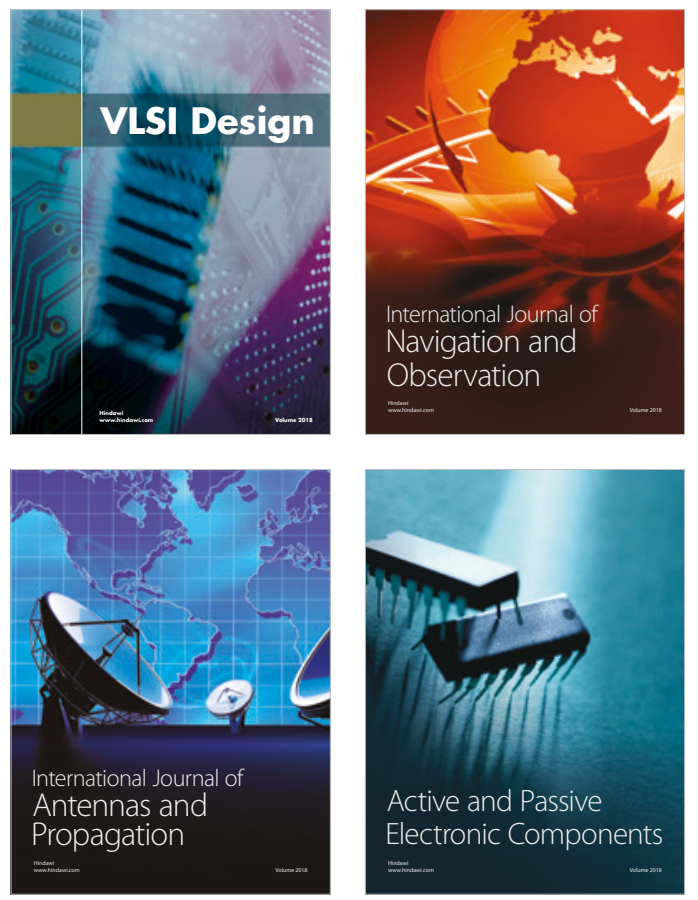
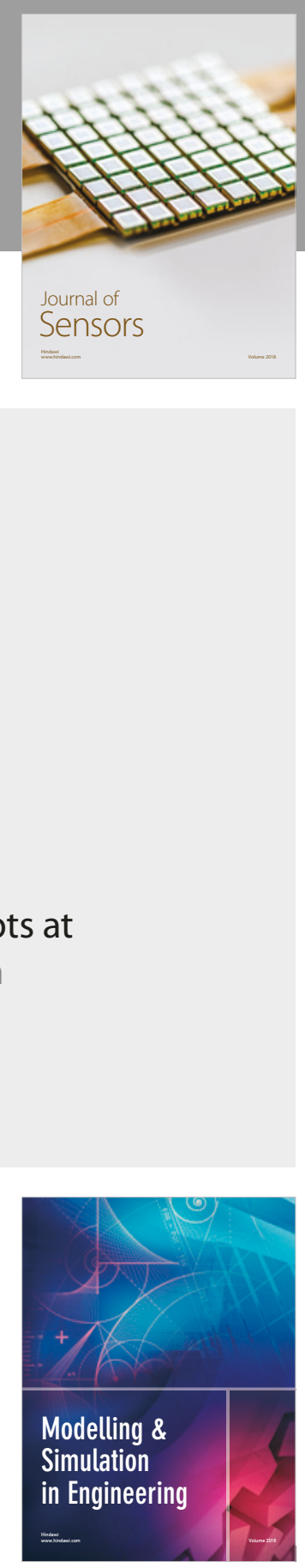

\section{Advances \\ Multimedia}
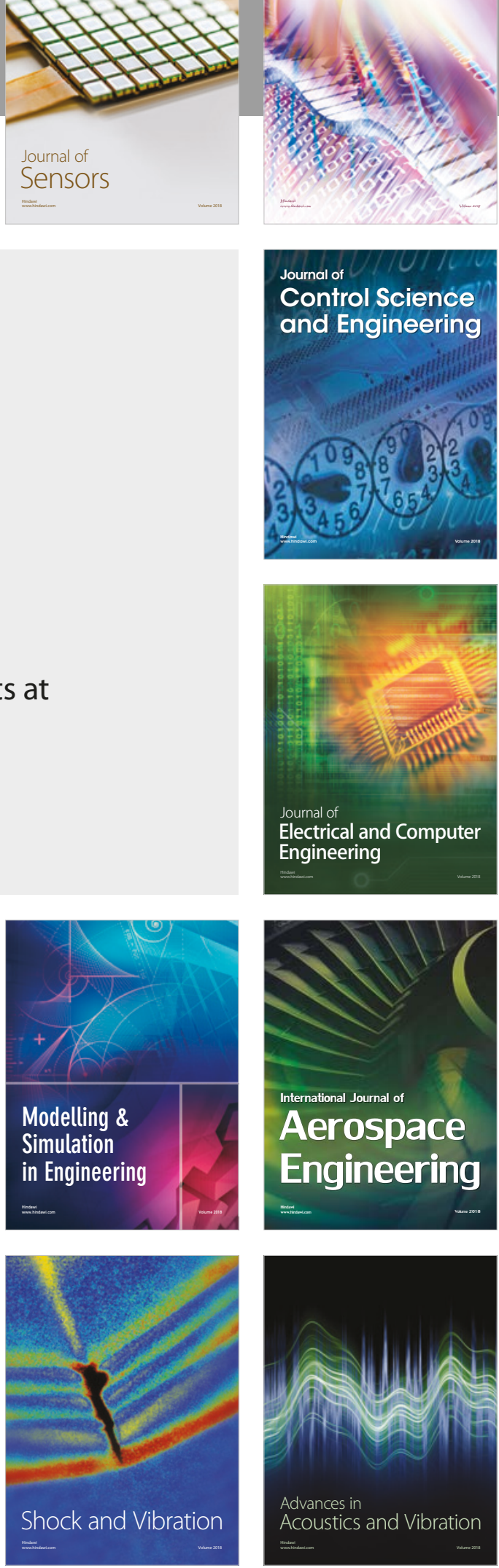